\title{
Does production of oil palm, soybean, or jatropha change biodiversity and ecosystem functions in tropical forests
}

Sini Savilaakso ${ }^{1 *}$, Yves Laumonier ${ }^{1,2}$, Manuel R Guariguata ${ }^{1}$ and Robert Nasi ${ }^{1}$

\begin{abstract}
Background: Biofuels, or fuels derived from transformation of biological matter, are hailed by some as a promising source of renewable energy potentially reducing greenhouse gas emissions. A widespread adoption of biofuels will however present its own set of challenges and consequences. Direct or indirect land use change due to expansion of feedstock cultivation can cause deforestation and forest degradation leading to biodiversity losses and other environmental concerns like soil degradation and erosion, water pollution and scarcity, and the risk of crop species invading natural ecosystems.

Although biofuel production is currently not the main use of palm oil and soybean and hence, has so far contributed only little to the land-use change patterns, it has been predicted to grow. Therefore, it is important to know the potential consequences of the expansion of biofuel cultivation may have for biodiversity in order to provide policy guidance.

Methods/design: In this review, we will assess the current state of knowledge of the impact of three first generation biofuel crops - oil palm, soybean, and jatropha - on the biodiversity and ecosystem functions of the tropical forests. We will look at the additional comparison of impacts from industrial versus smallholder plantations, and will compare the mitigation potential of different standards related to biofuel production. We will consider both qualitative and quantitative primary studies as well as descriptive reports that compare land conversion for target crop production with other land uses or land cover types. Both before/after and site comparison studies will be included, and biodiversity indicators to be assessed are species richness, abundance, and plant and animal community composition. If there is enough data, quantitative meta-analysis will be performed. Otherwise results will be summarized narratively.
\end{abstract}

Keywords: Biodiversity, Biofuels, Ecosystem function, Environmental impact, Jatropha, Oil palm, Plantations, Soybean, Species richness, Good practice standards, Tropics

\section{Background}

During the recent decade there has been a growing interest in bioenergy, especially biofuels, driven by concerns about global climate change, growing energy demand, and depleting fossil fuel reserves [1]. Energy derived from plant material, such as sugarcane and oil palm, offers, at least in theory, a promising way to answer part of our energy demand without increasing our greenhouse gas (GHG) emissions. In addition, biofuel production can create

\footnotetext{
* Correspondence: s.savilaakso@cgiar.org

${ }^{1}$ Center for International Forestry Research, Jalan CIFOR, Situ Gede, Sindang

Barang, Bogor (Barat) 16115, Indonesia

Full list of author information is available at the end of the article
}

additional income for the rural poor and advance economic development [2].

Nevertheless, biofuel based opportunities do not come without concerns. Direct or indirect land use change due to a wide expansion of biofuel cultivation can result in deforestation and destroy natural habitats $[3,4]$ which in turn may lead to the loss of biodiversity $[5,6]$. Other environmental concerns include soil degradation and erosion, water pollution and scarcity, and species' potential to invade natural ecosystems [3]. Furthermore, biofuel production can cause greater GHG release than the use of fossil fuels depending on the feed stock, energy intensity of

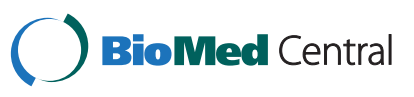


the production process, and land type converted to biofuel cultivation $[7,8]$. Potential negative social aspects include rising food prices and shortages of food supply, land tenure conflicts, and insufficient production remuneration $[2,9]$.

The debate surrounding biofuel production, especially in the tropics, has been highly polarized [10]. In the proposed review we intend to assess objectively the current state of knowledge of the impact of three first generation biofuel crops (oil palm, soybean, and jatropha) on biodiversity in the tropics. We use the broad definition of biodiversity as defined in the Convention of Biological Diversity: "Biological diversity means the variability among living organisms from all sources including, inter alia, terrestrial, marine and other aquatic ecosystems and the ecological complexes of which they are part; this includes diversity within species, between species and of ecosystems". Thus we will assess the effects of biofuel crops in three different levels: landscape, ecosystem, and species level. First, we will study the direct impact of crop plantations due to forest fragmentation and deforestation (i.e. forest conversion) on species abundance, diversity and composition. Also, we will include studies on ecosystem functions as these reflect changes in the ecosystem. Second, as the impact on biodiversity may differ under different production models, we will also compare industrial plantations and smallholder plantations. If we find negative impacts of biofuel crop cultivation on biodiversity, we will study different standards related to oil palm, jatropha, and soybean to find out how well these standards mitigate the impacts.

We recognize that biofuel production is currently not the main use of palm oil and soybean and hence, has so far contributed largely in an indirect way on the observed land-use change patterns $[1,6]$. However, as biofuel production is likely to grow significantly [11], it is important to know what are the potential consequences of an expansion of biofuel cultivation for biodiversity in order to provide informed policy guidance.

\section{Objective of the review \\ Primary question}

Does production of oil palm, soybean, or jatropha change biodiversity and ecosystem functions in tropical forests?

\section{Secondary questions}

Is there a difference in the impact on biodiversity between industrial plantations and smallholder plantations per volume of fuel produced?
Do different standards related to oil palm, jatropha and soybean mitigate the negative impacts?

\section{Methods/design \\ Searches}

The search aims to capture as comprehensive as possible a sample of literature published in peer-reviewed journals as well as other relevant literature. The following literature databases will be searched: Biofuels abstracts database by CABI, Web of Science, LAN TEEAL (Agriculture and natural resource management), and Directory of Open Access Journals.

In addition, the following internet search engines will be used in order to maximize coverage: Google, Google Scholar, and Scirus [12-14]. Literature will also be searched in the websites of relevant organizations such as the Food and Agriculture Organization (FAO), the International Finance Corporation (IFC), the United Nations Framework Convention on Climate Change (UNFCCC), the World Resources Institute (WRI), the International Institute for Environment and Development (IIED), the International Union for Conservation of Nature (IUCN), the Rights and Resources Initiative, and the World Wildlife Fund (WWF). Bibliographies of articles included in the review and previously published reviews will be checked for references. Recognized experts and key stakeholders will be contacted to provide further recommendations and information. The protocol will be updated if any additional source of information outside those listed is used.

The following search strings and their translations in French, Spanish, German, Swedish, and Finnish will be used: (oil palm OR soybean OR jatropha) AND tropic* AND "species diversity" OR "species richness" OR "species abundance" OR "species similarity" OR "species composition" OR "community composition" OR deforestation OR "land use change" OR fragmentation OR habitat loss OR connectivity OR "functional diversity" OR ecosystem OR displacement. Variation in spelling of search terms will be checked. All returned hits from academic databases will checked for relevance. When searching the internet, only the first fifty hits will be checked.

\section{Study inclusion criteria}

The criteria listed below will be used to assess the title, keywords, and the abstract for relevance. If there is uncertainty whether an article should be included or not based on the title, keywords, and the abstract, the article will be read in full to determine suitability. Studies that have data about a relevant subject, intervention and outcome, along with a valid comparator will be included if they fulfill the quality criteria listed in Table 1. 
Table 1 Hierarchy of quality of evidence based on the information provided in the documents

\begin{tabular}{ll}
\hline Category & Quality of evidence presented \\
\hline II & $\begin{array}{l}\text { Randomized controlled trials of adequate spatial and temporal } \\
\text { scale for the study species }\end{array}$ \\
Controlled trials without randomization with adequate \\
spatial and temporal scale for the study species \\
Comparisons of differences between sites with and without \\
controls with adequate spatial and temporal scale for the \\
study species.
\end{tabular}

Modified after Pullin and Knight [15].

Primary study question: does production of oil palm, soybean, or jatropha change biodiversity and ecosystem functions in tropical forests?

Geographical location: Study area should be within the tropics $\left(23.438^{\circ} \mathrm{S}\right.$ to $\left.23.438^{\circ} \mathrm{N}\right)$.

Relevant subject(s): Faunal and floral species.

Types of intervention: Conversion of the land to cultivate oil palm, soybean, and jatropha for any purpose.

Types of comparator: Other land use or land cover (primary forest, logged over forest, secondary forest (i.e. regrowth forest), shrub land, grassland, cropland). Ideally a study would compare current land use with previous land use but as those types of studies a rare, we will accept studies that have a reference site close enough to the converted site so that ecological conditions in study sites remain similar.

Types of outcome: Change in biodiversity indicators (relative species richness and abundance, species composition) and ecosystem functions.

Types of study: Qualitative and quantitative primary studies as well as descriptive studies and reports.

\section{Secondary study question 1: is there a difference in the impact on biodiversity between industial plantations and smallholder plantations per volume of fuel produced?}

Geographical location: Study area should be within the tropics $\left(23.438^{\circ} \mathrm{S}\right.$ to $\left.23.438^{\circ} \mathrm{N}\right)$.

Relevant subject(s): Faunal and floral species.

Types of intervention: Conversion of the land to industrial plantations to cultivate biofuel crops.

Types of comparator: Smallholder plantations.

Types of outcome: Change in biodiversity indicators (relative species richness and abundance, species composition) and ecosystem functions.

Types of study: Qualitative and quantitative primary studies as well as descriptive studies and reports.

\section{Secondary study question 2: Do different standards related to oil palm, jatropha, and soybean mitigate the negative impacts?}

Geographical location: Study area should be within the tropics $\left(23.438^{\circ} \mathrm{S}\right.$ to $\left.23.438^{\circ} \mathrm{N}\right)$.

Relevant subject(s): Different standards related to biofuels. Types of intervention: Standard in place should mitigate the impact of crop cultivation on biodiversity.

Types of comparator: Standards will be compared against each other to clarify how they mitigate the impact on biodiversity.

Types of outcome: Preferable outcome of any given standard is that it will mitigate any negative impact and enhance positive impacts within and nearby production area.

Types of study: Standards related to oil palm, jatropha, and soybean, i.e. international legislation, industry standards, ISO management standards, NGO standards.

\section{Potential effect modifiers and sources of heterogeneity}

Spatial and temporal scales can affect study outcomes as can different environmental conditions of the study sites. Hence, potential effect modifiers and sources of heterogeneity are listed below. Furthermore, surrounding landscape can influence the direction and intensity of a change.

Temporal and spatial scale
Altitude
Soil properties
Surrounding landscape
Original vegetation
Hunting intensity
Herbicides
Insecticides
Rodenticides
Fertilizers
Rotation time
Plantation management (industrial vs. smallholders)
Plantation size
Plantation type

\section{Article screening}

First reviewer will check all hits for relevance based on the title and keywords. After the first selection, abstracts of the remaining articles will be read to further determine the suitability of the articles for the review. The selected documents will then be read in full to determine their suitability for the review. At the beginning of the literature selection phase, kappa analysis will be undertaken to assess reviewer bias in the selection phase and to assure that study inclusion criteria are used consistently. 


\section{Study quality assessment}

An ideal study for this review would have sampled the area before and after the land conversion. The sampling would have been long enough to take into account seasonal variation and it would have been spatially extensive. However as such studies are not common, we will include all studies that fulfill the inclusion criteria. To avoid misleading conclusions due to the variation in the general study design, the studies will be weighted according to the hierarchy of quality of evidence (Table 1). Studies that fall into the category VI will be excluded from the analysis.

\section{Data extraction strategy and synthesis}

For the analysis we will categorize the data using the following five categories: mammals, birds, amphibians and reptiles, invertebrates, and plants. If we find enough studies on plants they will be classified according to plant functional groups.

The estimates of species richness and abundance and their means and standard deviations will be extracted to a spreadsheet. Also, species similarity indices will be extracted. If information about the type of species that cause dissimilarities in the species composition, e.g. forest, edge, or light-demanding species, is available, it will be extracted and categorized accordingly. In regard to ecosystem functions the change and its direction (negative or positive changes) will be recorded. Finally, information about the potential sources of heterogeneity will be included in the spreadsheet and if enough data for any of the categories will be found it will be taken into account in subsequent data analyses. Where insufficient data is provided for extraction, we will contact authors to acquire additional data.

If there is insufficient amount of data to perform meaningful statistical analyses on biodiversity indicators or ecosystem functions, we will summarize the data narratively. At a minimum we will present narrative synthesis tables that will list all included studies together with key characteristics, including critical appraisal of methodology.

The data will be categorized according to the subject, comparator and outcome. We will also summarize the requirements to mitigate impacts related to biodiversity in different standards.

\section{Competing interests}

The authors declare that they have no competing interest.

\section{Acknowledgments}

Three anonymous reviewers provided useful suggestions to improve the protocol to conduct the systematic review. Gillian Petrokofsky and Wen Zhou helped to prepare the protocol for publication. Center for International Forestry Research funded this review with partial support from the Government of Finland.

\section{Author details}

${ }^{1}$ Center for International Forestry Research, Jalan CIFOR, Situ Gede, Sindang Barang, Bogor (Barat) 16115, Indonesia. ${ }^{2}$ CIRAD Agricultural Research for Development, Avenue Agropolis, Montpellier Cedex 5 34398, France.

Received: 26 July 2013 Accepted: 25 August 2013

Published: 11 September 2013

\section{References}

1. Rajagopal D, Zilberman D: Review of environmental, economic and policy aspects of biofuels, World bank policy research working paper 4341. Washington, DC: The World Bank; 2007.

2. Feintrenie L, Kian Chong W, Levang P: Why do farmers prefer oil palm? Lessons learnt from Bungo district, Indonesia. Small-Scale Forestry 2010, 9:379-396.

3. Lewandowski I, Faaij A: Steps towards the development of a certification system for sustainable bio-energy trade, Report NWS-E-2004-31. Utrecht: Copernicus Institute of Sustainable Development and Innovation; 2004.

4. Koh LP, Ghazoul J: Biofuels, biodiversity, and people: understanding the conflicts and finding opportunities. Biol Cons 2008, 141:2450-2460.

5. Danielsen F, Beukema H, Burgess ND, Parish F, Brühl CA, Donald PF, Murdiyarso D, Phalan B, Reijnders L, Struebig M, Fitzherbert EB: Biofuel plantations on forested lands: double jeopardy for biodiversity and climate. Conserv Biol 2008, 23:348-358.

6. Phalan B: The social and environmental impacts of biofuels in Asia: an overview. Appl Energy 2009, 86:S21-S29.

7. Fargione J, Hill J, Tilman D, Polasky S, Hawthorne P: Land clearing and the biofuel carbon debt. Science 2008, 319:1235-1238.

8. Gibbs HK, Ruesch AS, Achard F, Clayton MK, Holmgren P, Ramankutty N, Foley JA: Tropical forests were the primary sources of new agricultural land in the 1980s and 1990s. PNAS 2010, 107:16732-16737.

9. Naylor RL, Liska A, Burke MB, Falcon WP, Gaskell JC, Rozelle SD, Cassman KG: The ripple effect: biofuels, food security, and the environment. Environment: Science and Policy for Sustainable Development 2007, 49:30-43.

10. Koh LP, Wilcove DS: Oil palm: disinformation enables deforestation. Trends Ecol Evolut 2008, 24:67-68.

11. Food and Agriculture Organization of the United Nations: Forests and energy, FAO Forestry Paper 154. Rome: The Food and Agriculture Organization of the United Nations; 2008.

12. Google www.google.com.

13. Google Scholar www.scholar.google.com.

14. Scirus www.scirus.com.

15. Pullin A, Knight TM: Support for decision making in conservation practice: an evidence-based approach. J Nat Conserv 2003, 11:83-90.

doi:10.1186/2047-2382-2-17

Cite this article as: Savilaakso et al:: Does production of oil palm, soybean, or jatropha change biodiversity and ecosystem functions in tropical forests. Environmental Evidence 2013 2:17.

\section{Authors' contributions}

SS designed the study and drafted the manuscript. YL participated in the study design and helped to draft the protocol. MRG participated in the study design and helped to draft the protocol. RN had the idea for the study. He participated in its design and helped to draft the protocol. All authors read and approved the protocol. 